\title{
The Dyad and the Third Party: The Traces of Simmel's Distinction in Phenomenology and Family Studies ${ }^{1}$
}

\author{
Elizaveta Kostrova \\ Saint Tikhon's Orthodox University in Moscow \\ elizakos@mail.ru \\ Received 1 March 2018; accepted 4 June 2018; published 30 September 2018.
}

\begin{abstract}
The paper confronts Georg Simmel's distinction between the dyad and the triad with the phenomenological analysis of analogous structures undertaken by E. Lévinas, B. Waldenfels, and J.-L. Marion. Simmel insists on keeping the dyad and the triad apart while only the triad is considered worthy of sociological research. On the contrary, phenomenologists reveal deep interrelation between the relationship with the other and the third party where the latter is actually co-present in the dyad. The presupposed link between the two and the three implies a different understanding of sociality that would respect its members in their uniqueness, unlike the world of interchangeable individualities common for social science. The third party can appear as the dimension of law and the ordinary (in Waldenfels), as the other of the other and the figure of humanity (in Lévinas), or as the child in the case of erotic relationship (in Marion). The last aspect of the third party provides a link to family studies. A brief outline of the situation illustrates oscillation between the triadic and dyadic interpretations of the family with the apparent prevalence of the dyad in recent decades.
\end{abstract}

Keywords: community; family studies; intimacy; Lévinas; Marion; phenomenology; reciprocity; Simmel; the other; the third party; Waldenfels.

\section{Introduction}

More than a hundred years ago, Georg Simmel drew a line between the dyad and the triad for social theory and formulated the sources of the distinction which has since become classical (see, for example, Tyrell, Rammstedt, \& Meyer, 2011, p. 225). According to Simmel,

\footnotetext{
${ }^{1}$ This research was supported by the Russian Science Foundation research grant No. 18-78-10089 and was conducted in St Tikhon's Orthodox University (Moscow).
} 
a group of three elements is the basic and the minimum unit of the social. The "weird" dyad with its secret chemistry between the two is not denied but belongs to the region of the transient and elusive. It can be of interest to psychology or art; however, it is excluded from the scientific consideration of society, as it can never produce anything "social."

Though rejected by Simmel, the relationship of the two has proved fruitful in the framework of philosophical discussion, in particular in phenomenology, which suggests a way to approach the regions inaccessible to scientific method. In this case, phenomenological analysis has opened an alternative view on the interrelation between the dyad and the triad (or the other and the third party). Furthermore, this new perspective has had fundamental implications for the interpretation of the social.

In Simmel, the dyad and the triad are strictly separated. Unlike the former, the latter is treated as a superpersonal structure that does not depend on the elements it is composed of; the specific elements themselves are not of much importance and could be replaced. Society appears to be formed by a quantity of equal (alter) egos. Taking the otherness of the other seriously, phenomenology discovers the co-presence of the third in the relation of the unique, unequal, and irreplaceable two - thus providing a fundamentally different understanding of the social.

Interpreting people as atoms devoid of unique characteristics has formed the basis of social science and ensured its productivity. Nevertheless, if we recognize that phenomenological analysis traces something substantial, then it is obvious that important-perhaps the most important - things are neglected by this approach. As an illustration, I use research on fatherhood and try to identify some pain points that could probably be cured with the help of another perspective. Forming a borderline between the private and the public, the individual and the social, the family can serve as a good example in this context.

In this paper, I contrast the view on the interrelation between the dyad and the triad in phenomenology with the one presented by Simmel and characteristic of social science. In addition, I try to look for some parallels and congruence in family research (especially fatherhood studies). I start with a brief presentation of Simmel's theory, which is not only the first chronologically but, in my opinion, gives a fine introduction to the third party in general. Simmel considers and sums up the main formal moments that distinguish the dyad from the triad, and thus can serve as the initial frame of reference for the phenomenologists who complicate and deepen the distinction. The subsequent sections offer an overview of the phenomenological analysis of structures analogous to Simmel's dyad and triad in B. Waldenfels, E. Lévinas, and J.-L. Marion. Marion's discussion of the child as the third party serves as a link to the last section, in which I try to show the problematic status of the family in science. Surely reflecting the complex reality of the modern family, these ambiguities, in my opinion, also echo the difficult choice between the dyadic and triadic structures. 


\section{Marking the Boundaries: Georg Simmel}

One of the forefathers of sociology as science, Georg Simmel was probably the first to analyze the third party properly. He does it in his "Sociology" of 1908 while trying to determine the most important formal characteristics of what he calls "Vergesellschaftung," that is, association. The content, or the "matter," of socialization is all that is present in individuals as their mental characteristics, desires, aspirations, fears and the like-everything that makes them act. The "matter" is not social and should not be of interest to sociology, while the form is exactly what sociology should deal with.

Quantity is one of the categories he refers to in this context. In the most general sense, he is talking about the meaning of the number of elements for a group. Simmel illustrates the importance of quantity via receiving guests: how many people do we need to get what we call a "society," and not a friendly evening in a narrow circle? This question seems to be like an aporia about how many grains make a heap. However, Simmel does not consider drawing a line between "society" and "non-society" unsolvable for sociology and takes up the challenge.

Taking into account the key importance of interaction for sociology, one could assume that the two will be the basic unit. It seems to suit sociology best of all as a huge number of social phenomena require just two participants, but Simmel refuses to recognize the primary unit of the social in the dyad. In his opinion, in such a case the participants do not have a sense of belonging to some superpersonal reality that is not dependent on them. The fact is that the exit or death of anyone of the two destroys the existing link immediately and completely, and the premonition of the end gives a special color to any relationship of the two. This creates an atmosphere of intimacy, fragility, and uniqueness, despite how often similar relationships existed in human society. The two are driven to each other, their personal individual characteristics, opinions, and traits of character - in short, the aforementioned "matter" plays a huge role in the emergence, preservation, and termination of companionship. It is characteristic that, in this context, Simmel prefers to talk about a "relationship" (das Verhältnis): this is in opposition to the "interaction" (die Wechselwirkung) that constitutes the basis of society and applies to individuals as well as groups, nations, states, etc. From relationship, unlike interaction, neither reproduction of structures nor independent collective formations can occur, which are both necessary for the existence and development of society.

So, the minimal group, which leads to the emergence of a superpersonal social level, should consist of three elements:

Dyads thus have very specific features. This is shown not only by the fact that the addition of a third person completely changes them, but also, and even more so, by the common observation that the further expansion to four or more by no means correspondingly modifies the group any further. (Simmel, 1950, p. 138)

It is worth mentioning that in his early works, Simmel had already observed the internal association of community that is often built on the basis of an attitude toward some external third party. In most cases, such a cohesive agent is hatred of a common enemy. 
However, the opposite is also possible: Simmel cites the example of the Czech Brethren, united by a common love for Christ.

The third participant brings a new dimension to the relationship of the two, provides objectivity and superpersonality, and opens up the space of publicity. Thus, the exclusiveness of the love of two people acquires a social dimension when it transforms into family through marriage, thanks to the introduction of diverse "third elements": those who are involved in the wedding preparation, the priest who is present at the marriage, the children who are born. No dyadic model allows us to reconstruct society as convincingly as the triad does. The uniqueness characteristic of the relationship of the two is lost, but the dependence on each other also decreases.

Further deepening of the analysis is achieved not by increasing the number but by appealing to the various functions of the third party: a parasite, the audience, a traitor, etc. In this way, Simmel identifies three main possible roles of the third party. First of all, he can act as an intermediary: without entering into any of the antagonistic parties but being interested in their reconciliation he can help resolve the conflict. With some reservations, the role of a judge can be an example of such a situation. The third person can not only work to resolve the conflict, he may well be its source, as in a "divide-and-conquer"-situation or with the beneficiary as "the rejoicing third." An example of the former is a manipulator that provokes conflicts in order to strengthen his own position. A good example of the "rejoicing third" would be a consumer who benefits from the competition of enterprises, or a woman who happens to be the object of desire for two rival men.

So, Simmel has introduced the distinction between the dyad and the triad and defined it as the borderline between the social and the non-social. The addition of the third element disconnects the intimacy of the two making it public whereas in the dyad nothing transcends the unique characteristics of the participants. Triadic structures, first of all, are much more stable and, what is probably more important for Simmel as a sociologist, they generate a formally neutral relation that can be studied and described. The elements are considered equal, independent, and interchangeable which makes them easy to manipulate. In light of his sociology, the unique singularity of elusive reciprocity could be, perhaps, a subject of psychology, but not sociology. It is also noteworthy that the transition from a dyad to a triad is carried out, so to speak, by simple summation: the third element is added, introduced from the outside. The dyad and the triad remain separate and do not depend on each other.

Having presented Simmel's interpretation of the third party and the way it transforms the dyad, I would like to turn to the phenomenological perspective. I choose the conceptions of Bernhard Waldenfels, Emmanuel Lévinas, and Jean-Luc Marion as all of them explicitly discuss the constellation of the two and the three. Though highly significant, questions concerning their mutual influences are beyond my consideration. Instead, I would like to follow their thought as they expose the hidden link between the dyad (which is the start and the center of their philosophy) and the third party that seems to have escaped Simmel's attention. 


\section{The Indispensable Order: Bernhard Waldenfels}

Bernhard Waldenfels's conception may be the best to start the comparison. The third party occupies an important place in his "responsive phenomenology." Since he confines himself to a specific aspect of the relationship between the self and the other, namely to the careful phenomenological analysis of discourse as the main expression of this relationship, his course of thought is more transparent. In responsive phenomenology, one can find all the main motives of the phenomenological interpretation, and both the affinities and the dissimilarities with Simmel show themselves clearly.

The other is significant to Waldenfels as far as he is an "alien" and not an individual instance of multiplicity. Only absolute otherness as the "extra-ordinary" allows for situations of responsivity. Whereas the (numeric) other is constructed in opposition to the same by the same itself on its way to self-determination, the alien can actively distinguish itself from me. In this sense, the alien does not coincide with the "Not-I." However, the alien is not an alter ego either. The alien appears as a violation of the rules, as literally the "extraordinary," which exceeds my expectations. Therefore, Waldenfels distinguishes conversation with the other as the alien from dialogue in its usual sense because in the latter there is always a distribution of roles - which can be analyzed successfully by, for instance, communication theory. On the contrary, the claim of the other is unpredictable and comes as a surprise from out there (von anderswoher), from the non-place of the alien.

Waldenfels starts with the statement that intentionality is not suitable for catching the alien as it is (Waldenfels \& Därmann, 1998, p. 40). The claim of the other escapes the normal order and thus does not make sense and does not follow the rules. That is why one has to leave the limits of traditional phenomenology while answering its appeal (Waldenfels \& Därmann, 1998, p. 42).

The discourse is constituted by the "claim" (der Anspruch) or "call" of the other and my answer. The other expresses himself as the alien in his appeal to me, that is, by the mere fact that he is addressing me present in every conversation beyond its concrete content. The experience of the other manifests itself only indirectly and can occur in various forms, like surprise, fear, or anxiety (Waldenfels, 2006, p. 125). The other makes me feel that no one is ever quite at home (Waldenfels \& Därmann, 1998, p. 37).

The very perception of this call is already the beginning of an answer: accordingly, the absence of an answer, the refusal to respond belongs to responsivity just as well as a given answer. In the latter, Waldenfels distinguishes between the "answer" as specific content, a reaction to the message contained in what is said, and the "response." It is response that is of greatest interest, since it is precisely the answer in the proper sense: it corresponds to the appeal to me that was behind this or that specific content of the call. It does not carry any information and does not fulfill any request, but it forms the ability to respond to the appeal of another that is essential for a person (Waldenfels \& Därmann, 1998, p. 45). In this sense, I have no choice: as already mentioned, I can ignore the claim, but I cannot help responding. 
Dialogue, in its traditional sense, puts me and the other on an equal footing, while the claim and the response that Waldenfels talks about imply a fundamental asymmetry. Furthermore, the response with its inequality precedes the usual dialogue and makes it possible.

Waldenfels emphasizes, with reference to Lévinas, the incompatibility and asymmetry between the claim and my response. They belong to different dimensions and do not have a common denominator. It is only from the outside that one can perceive them as moments of mutual exchange, but this perspective also destroys the specific singularity and uniqueness of this particular responsivity.

Within this framework, the third party also has its place. Whatever we say or do, we cannot proceed without bringing in the third party (Waldenfels, 2006, p. 126) that can appear as a theme, as a witness, as an observer, as a leader, as a translator, etc. (Waldenfels, 2016, p. 293ff.) Most important is his role as the source of law and order. He is the one that can look at the responsivity of the self and the alien from the outside and therefore has the ability to compare and, if necessary, to reconcile them. From his perspective, the unique fits into a series of repetitive images and is brought under a general rule. The participation of the third party opens the possibility of the existence of order and laws, and at the same time, rights and justice (Waldenfels \& Därmann, 1998, p. 48).

As Waldenfels notes, the other always meets me already as the third, as well as I always turn out to be the third (1997, p. 116). This implies that each of us is determined by his belonging to the social environment and the inevitable acceptance of certain roles and functions that denote his gender, class, age, etc.- that is, one's membership in various groups. Even being a "neighbor" is revealed as a role in this sense; only the "alien" is never a role (Waldenfels, 1997, pp. 110-111). When I understand the other or myself through such definitions and treat him or myself accordingly, I look at the situation through the eyes of an outsider - through the eyes of a third person. It can be said that the third person corresponds to the social dimension, to the community, and to their exposure to general rules.

Waldenfels insists on the distinction between the alien and the third as the extra-ordinary one versus the one consistent with rules. The borderline between the dimensions of the other and the third party runs along the moment when we start talking about the other as "something" or "someone" (Waldenfels, 2006, p. 127).

According to Waldenfels, the third party "co-claims" in the other's appeal as the voice of law that sounds every time, in every call of the other as the alien. The other's intrusion actually presupposes the order exploded by his appearance (Waldenfels, 2006, p. 125). However, any law is an order and as such is unfriendly to the "extra-ordinary." Thus, a moment of injustice intrinsically belongs to every form of justice as making equal what is unequal (Waldenfels, 1997, p. 126). This is the inevitable, constitutive moment of any contingent order; the hard task is to remember about its contingency, to keep yourself alert to the other's appeal, and to allow his claim to call you into question (Waldenfels, 2006, p. 128). 
At first sight, Waldenfels's interpretation is consistent with Simmel's. He seems to allot different orders to the dyadic and the triadic relations and, above all, identifies the third party with the social dimension it opens. However, on closer inspection, some important dissimilarities become obvious. Firstly, Waldenfels demonstrates how to explore the dyad without taking into account any concrete individual properties of the situation. It is thus possible to find a superpersonal structure beyond all "psychology" (asymmetry being one of its main characteristics). Secondly, the third party appears to be necessary to the dyad because the discourse inevitably proceeds in a world pervaded by his presence. Thirdly, unlike Simmel, Waldenfels insists that the dyadic and the triadic dimensions do not exist separately, without collisions; on the contrary, their crossing is not only possible, but continual and disruptive for both. Just like the third introduces his destructively egalitarian justice, the alien keeps breaking through order and law. Most importantly, this problematic interrelation should not be rectified but maintained and cherished in all its inconsistency.

\section{4. "The Whole of Humanity": Emmanuel Lévinas}

It is probably Lévinas who gives the most detailed and sophisticated analysis of the third party in phenomenology. He explicates most thoroughly what the phenomenological perspective on the third party implies for sociality and draws a picture quite different from Simmel's. In the long run, his aim is to lay the foundation for a different understanding of sociality, which would differ fundamentally from the generally accepted one. In short, he wants to show how the community could be created as "an addition of beings which do not make up a number with one another" (Lévinas, 1954/1987, p. 28), in contrast to the usual view of the set of identical individuals as the original reality. This is associated with a deep ethical motive: the rejection of the postulate of equivalent egoistical wills destroys the main foundation of conceptions that see the war of all against all as primordial and allows us to build sociality based on a primordial peace (Peperzak \& Lévinas, 1993, p. 180). In this sense, Simmel seems to belong to those from whom Lévinas seeks to dissociate himself.

According to Lévinas, the human community in so far as it is human is not based on the unity of the biological genus. To describe the community whose members are not interchangeable units aggregated on the basis of similarity but unique beings that are initially set in relation to each other in some way, he refers to the metaphor of family ties and speaks of "brotherhood" and "kinship of men." The point lies in understanding the peace as not an accidental phenomenon, arising as an unstable balance at the intersection of a multitude of autocratic multidirectional wills; solidarity turns out to be the prerequisite of equality, which precedes war, and it is the third party that plays a key role in this transformation.

We can say that the main goal of Lévinas's philosophy is to find a place for another person, that is, to make room for the other and to protect his freedom from impingements. This is not limited to physical violence or suppression of the other's will. The other should be free from the sphere of action of my concepts and all the machinery of my cognitive apparatus, 
which are themselves an abuse of power on the part of the ego and the source and foundation of all the more obvious forms of coercion. The other is no longer a phenomenon in the series of others, albeit with its own specific characteristics, but the face.

The other signifies the limit of my power and at the same time gives meaning to everything that I have and that I can now give as a gift. The isolated existence of the self in its closed world now loses its primacy and ultimacy. The I with its happy self-affirmation, the master of the world ready to overcome any resistance turns guilty in the eyes of the other. The face of the other puts a limit on the unfolding and triumph of my will. Just as his face slips out of the conceptual network of my thinking, the ban on murder which is read in his eyes requires respect and self-restraint. The face to face turns into an infinite responsibility of the I before the other.

It is important to note that for Lévinas, the relationship between the self and the other is essentially ethical. The specificity of proximity as facing the other is therefore contrasted with "intimate society" (Lévinas, 1954/1987, p. 30) which coincides with exclusive relations between the two as friendships and especially erotic relationships. The other and I are not united in the companionship of mutuality and reciprocity; the face to face is fundamentally asymmetric: the other is always higher than me, it is always "me for the other." The absoluteness of his otherness creates a distance which is resolved in discourse as alternative to violence. The fact that proximity is discourse brings to it a special kind of publicity that does not coincide with the usual "objectivity" and "observability," but clearly separates the face to face from the silent understanding (or "cooing") that takes place between I and Thou: "Everything that takes place here 'between us' concerns everyone, the face that looks at it places itself in the full light of the public order" (Lévinas, 1961/1979, p. 212).

The publicity in question, the "public order" which I enter as I overcome my egocentric isolation is the order of justice, and it is the presence of the third party that creates it. In Otherwise than Being, Lévinas (1974/1981) explicates the third party as "other than the neighbor, but also another neighbor, and also a neighbor of the other, and not just his fellow" (p. 157). It is characteristic that the boundary between Thou and the absolute otherness, that is, the difference between intimacy and ethics, is determined precisely by the figure of the third party ${ }^{2}$ that is co-present in the face: "The third party looks at me in the eyes of the other-language is justice" (Lévinas, 1961/1979, p. 213).

This publicity is of a special kind and differs from the mere presence of an observer. Moreover, the exclusiveness and uniqueness of what is happening between the other and me eludes the view from outside, so that the description from the "third person perspective" cannot convey anything but empty shells of concepts. However, the third party does not watch from the outside, but is already present in the face of the other when (if) it is revealed to me as such (and not as one of the phenomena of the environment or the object of erotic desire). To meet a face as a face means to see the third party in it, that is, "the whole of

\footnotetext{
${ }^{2}$ In his 1954 paper "The Ego and the Totality" (Lévinas, 1954/1987), the person that anticipates the main characteristics of the other is even called "the third man" / "the third party."
} 
humanity which looks at us" (Lévinas, 1961/1979, p. 213). Even if there is no one around us, by recognizing the other in another person I realize the weight of my actions and refuse to hide from responsibility.

The appearance of the third party brings to life questions and problems - as well as consciousness and thinking. I have to evaluate the needs of the other and the other others and balance my obligations and my responsibility towards each of them which means to compare the incomparable. The contiguity of the other and the third makes equality possible. The presence of the third party sets the limits of my infinite responsibility to the other. The asymmetry, the non-reciprocity of the face to face retains its fundamental importance because it allows one to distinguish this picture from numerous conceptions that understand the relationship between people and, ultimately, the emergence of the community as a result of mutual actions of individuals. Yet the figure of the third party gives me the hope to be the other for the other and to get justice for myself. ${ }^{3}$

In this way, justice is present in this proximity from the very beginning, rooted in it and impossible beyond and without it. Such an understanding of justice as arising from a meeting with the other leads precisely to the metaphor of "brotherhood" as primary and preceding "the human race": "My relationship with the other as a neighbor makes sense to my relations with all the others" (Lévinas, 1974/1981, p. 159). Although the state and its institutions are necessary, they cannot be justified if they lose awareness of their source in a true relation to the other. Similarly, limiting my responsibility to the other in light of the presence of the third party should not be considered degradation. Ultimately, it is only the asymmetry that makes justice possible: "The equality of all is borne by my inequality, the surplus of my duties over my rights. The forgetting of self moves justice" (Lévinas, 1974/1981, p.159).

Compared to Waldenfels's responsive phenomenology, Lévinas's analysis covers a wider scope and does not limit itself to the situation of discourse. The superpersonal aspect of the relationship of the two along with its deep interconnection with the third party persists, yet some more subtle distinctions come into play.

By the introduction of the third party, both Simmel and Lévinas seek to separate some superpersonal relation from the intimacy of the two. Nevertheless, the distinctions between the two visions of sociality are enlightening. Simmel's third element comes from the Hobbesian world of selfish independent egos: he can be malicious and could become both a conciliator and a source of conflict between the ego and his partner. The third party understood as the other of the other (or other others), however, retains the height and inviolability characteristic of the other.

This implies the existence of two different dyads in Lévinas's philosophy: an intimate one that functions as a monad, and an "ethical" one that is open to responsibility. It is the latter that forms the basis for community, gives us hope for a just society, and reflects Lévinas's

\footnotetext{
${ }^{3}$ The possibility of this outcome is assured by God.
} 
desire to show the link between politics and ethics (see Bernasconi, 2005). The "monadic" dyad seems to correspond quite well to Simmel's attitude towards asocial relationships. Silent and intimate, it belongs to the non-ethical and is distinguished from the "authentic" relationship. For this reason, the lover is not the face. Nevertheless, it turns out that the third party is co-present in the erotic relationship as well though differently. Lévinas referred to this in his phenomenology of Eros (Lévinas, 1961/1979, p. 254 ff.). The subject was afterwards developed at length by Jean-Luc Marion in The Erotic Phenomenon (2008).

\section{The Child as the Witness: Jean-Luc Marion}

The family is a common example of a triad that puts together a couple and a child. Already in Simmel, this is the most frequent illustration of the triad; for instance, as already mentioned in the part devoted to Simmel, he demonstrates the qualitative leap between the dyad and the triad, which occurs with the birth of the child turning a childless couple into a family - a leap that no longer occurs with a further increase in the number of children. Lévinas discusses the case of the erotic relationship to show its difference from the true face to face. At the same time, it is fraught with the anticipation of the other in his otherness incarnated as a child. Thus, Lévinas shows that even in the "intimate society," the third party can be somehow present. In The Erotic Phenomenon, J.-L. Marion picks up this theme to give his version of this transition. In this paper, I consider Marion's version of the analysis.

At a certain stage, the logic of the analysis reveals that the erotic phenomenon and the oath that lies at its core require faithfulness, and more than that-eternal faithfulness. To fall in love for a predetermined period of time or to say that you love someone while not intending to remain faithful forever means not to love; doing so would imply an internal contradiction. Meanwhile, this hardly ever happens in real life; most often lovers are too weak and volatile, and the erotic phenomenon ceases at some point. This does not deny its connection with the oath and the requirement of eternity contained in it, but rather it shows the lovers' failure. So usually one lives through a series of erotic phenomena: in each case, in the beginning there is a sincere desire for eternal faithfulness, which, however, breaks one day, so that everything has to start again. And even within the same relationship, erotic reduction must be constantly renewed, again and again.

Some relief can be brought by the arrival of the third party, which is the child in the context of the erotic phenomenon. He escapes the finiteness of love because he goes beyond it. However, as he still comes from our love and is involved in erotic reduction he can ensure its duration, confirming our oath. Thus, the child is the witness of our oath; his visibility is, as it were, the visibility of our oath and confirms, even if not able to reproduce it, that erotic reduction took place once, even if it ceases to be. The addressees of this visibility are not extraneous people outside of our relationship but, first of all, the lovers: the child "render[s] themselves visible to themselves" (Marion, 2008, p. 197). The flesh of the child is produced by the flesh of the lovers; nevertheless, the unobservable distance between the flesh of the one and the other which will never become one is incarnated in him as well, which is of 
fundamental importance. This distance expresses that the child does not coincide with his parents, and this is precisely what allows him to serve as a mirror for their love: "the child incarnates in her flesh an oath once and forever accomplished, even if the lovers have broken it subsequently. In the child, the oath is made flesh, once and for all and irrevocably" (Marion, 2008, p. 198). If the lovers break their own oath, the child that incarnated it will continue to testify against them "as a pledge against their separation" (p. 198).

The child shows himself as truly the third in his arrival and in facticity. He always comes as an "unpredictable arrival" destroying unceremoniously the mode of existence that prevailed before him. He breaks in autocratically as an "intruder," imposing himself, rearranging everything at his pleasure. Its facticity exceeds that of any other phenomenon as unforeseeable and irrevocable as it is. The child always manifests itself as not the one expected and resembles nobody: "the most foreign and the most intimate" (Marion, 2008, p. 200). Precisely as a result of this distance which constitutes the child as the third party, he can serve as a "mirror" of the erotic oath.

In his function as "producing a more stable visibility of the erotic phenomenon already accomplished by the oath and repeated by enjoyment, and thus of assuring the visibility of the lovers, as it is present and to come" (Marion, 2008, p. 197), the child is an integral part of the erotic phenomenon. The desire to exclude it would also mean the cessation of erotic reduction - just as when the lover gives a false oath.

The child as part of the erotic reduction is always the "possibility of the child" (Marion, 2008, p. 198). It is important to understand the child precisely as possibility because the event of his arrival never submits to the will of the parents and just "happens," "comes forward" (or does not happen) regardless of all that the parents and/or other people involved are undertaking to facilitate or avoid this.

It would seem that the arrival of the third party that apparently fixes an oath for us and for others and extends it beyond our faithfulness and even beyond our life allows us to put an end to the erotic reduction and to come out of the vicious circle of endless repetitions of the oath. But the child cannot "pronounce a last judgment" completing our love story: he stays a witness only for a while, and after that the child grows up. His body speaks no longer of our love, but of himself. And though his name is our name, it turns out that the child can play the role of the third party only "in transit." He goes away and takes his oath with him, making it a part of himself and leaving us with nothing. ${ }^{4}$

The inevitability of the child's departure comes from the fact that along with the lovers' oath, he embodies "all the impossibility of reciprocity between the lovers," that is, "the impossibility of rendering gift for gift" (Marion, 2008, p. 204). This goes back to the first lover's advance that was ready to meet the unknown without the hope of reciprocity. And as the child cannot repay the gift of life received from his parents, he "puts it in transit" passing it over to his own children not expecting any refund.

\footnotetext{
${ }^{4}$ According to Marion, the final witness is not excluded, but belongs to eschatological dimension.
} 
As already said, Marion's focus is the intimacy of the two and the way it is transformed by the arrival of the third party. Marion's analysis is instructive in that he considers, as though through a magnifying glass, what Simmel points out with broader strokes: how the secret becomes clear, how exactly the union of the two becomes objectively given. Erotic relationship is a prime example for the closed dyadic structure (though, in fact, any special relations with people you choose fall under this category). Precisely a loving couple, silent or "cooing" in its mutuality, serves as an antipole for the face to face encounter in Lévinas. And yet, it turns out that the two long for a witness - provided they are truly in love. The last refuge of the asocial dyad is no more secure.

\section{In Search of the Third Wheel: Family Studies}

Presenting his phenomenological interpretation, Marion does not deny all the other aspects of childbirth with the usual assessment of its effects for society and community but leaves them to sociology. He distances himself from the views prevalent in social science and positions which are obviously quite different from what he is interested in. Nevertheless, I would like to contrast the phenomenological findings discussed above with some motives from social science. In my opinion, family studies is the best choice for comparison. Firstly, it has already been mentioned that family was repeatedly and explicitly referred to as a link between the two and the three. One could assume that family studies would have something to do with the problem of quantity and structure. Secondly, family has often been placed on the border between the individual and the social. It could therefore be especially intriguing to see what the common premises of family studies imply.

In search of parallels to the problem of the third party, I have opted for fatherhood studies. On the one hand, they are less numerous and easier to observe; on the other hand, this can also be justified by the definitely male perspective on the erotic phenomenon as it is analyzed by Marion (or Lévinas).

Family studies give a curious and contradictory picture. Finding some reflection of the dyadic-triadic structure of the family in family studies is not an easy task.

Both Simmel and (probably to a lesser degree) Marion have in mind a very conservative family image that is no longer self-evident. It goes well with Parsons's views of the traditional role distribution in the family that used to dominate the sociology of the family. That was a time when the family was mostly perceived in its structure and the internal relations between the elements were ignored. Under this perspective the family was actually seen as a triad. Nevertheless, its structure was quite different. In the eyes of Simmel and Marion, it is obvious that the child is the third party in the family who bursts into the intimacy of the couple and transforms it into a family. At the same time, in the context of family research, this perspective is a relatively recent achievement. Just a few decades ago, it would have been more logical to describe the mother as the third party playing the role of an emotional mediator between the child and the father, or, even more likely, the father who turns out to be almost excluded from the close mother-child relationship. In psychotherapy, Ernest L. 
Abelin (1971) formulates a similar message: according to Abelin, the father's mission is to open a way into the big world for his child - away from its intimacy with the mother. Accordingly, for a long time, though technically admitting the triadic structure of the family, family research has actually been limited to mother-child relationships.

Since then the understanding of family, its role, and its place has changed dramatically. The perspective of previous era was called into question. Family as a closed separate unit was criticized theoretically (for example, by feminist thinkers), undermined legally (for example, putting only the mother at the center of family policies), and eroded practically (with growing popularity and most surprising designs of non-conformist ways to construct a family). As a result, researchers tend to present the family as a sum of dyadic relationships (relations between spouses, mother-child, and father-child relationships). Marriage and parenting are actually studied separately.

In addition, due to methodological prerequisites, studying the triad in its proper sense is as yet hardly possible and, in any case, extremely difficult. However, one can find some isolated results that seem to pay tribute to all participants in the triad. These include, for example, studies of the ways relationships in a couple change after or as a result of the birth of a child (Doss, Rhoades, Stanley, \& Markman, 2009), or observations of changes in the behavior of parents with their child depending on whether the second parent is present during their interaction (Pedersen \& Society for Research in Child Development [SRCD], 1980). In the context of traditional "omission" of fathers, the revival of interest in the role of the father and the father-child relationship observed in modern research can also be considered a return to understanding the family as consisting of (at least) three elements. The need to expand the perspective has been realized in family psychotherapy as well (see e.g., Whitaker, 1989).

On the whole, the modern perception of family relations tends to increase the value of intimacy and, perhaps, serves as additional reinforcement for the focus on dyadic connections. Although the problematic nature of such an approach is partly realized, it retains its positions despite criticism. The attention of researchers turns from the household as a whole to the relationships of two individuals within households: to a couple as the foundation of a nuclear family or, say, the mother-child relationship. Thus, it is characteristic that many fathers who opted for more participation in the upbringing of their children seem to do so for the sake of building relationships that are more reliable than those with their partners (Gatrell, 2005, p. 131). This observation is telling as it both echoes Marion's analysis and goes against his logic.

It is the formation of intimate relationships with the child, especially on the part of the father, that can be considered a new trend. The value of intimacy is recognized by an increasing number of parents, even if not all of them are taking significant steps to achieve it. The researchers themselves are inclined to presume the significance of precisely this kind of dyadic intimate relationship. For example, F. Pedersen observes that left alone with the child, fathers behave in much the same way as mothers but change their behavior towards a more distant and more "appropriate" traditional role of the father in the presence of the 
mother. Pedersen supposes, then, that it is not so much the amount of time spent with the child but the amount of time with nobody around that plays a key role in building a close relationship with the child (Pedersen \& SRCD, 1980, p. 80). As noted by E. Dermott, "The model of contemporary fatherhood which emerges is [...] closer to the ethic of the pure relationship than an ethic of caring responsibility" (2008, p. 142). It is curious that this process goes in parallel to the one by which the child ceases to be the third party and intruder in the eyes of the father and becomes the second pole in their dyadic "intimate society."

\section{Conclusion}

In this paper, I have tried to outline the main interpretations of the role and significance of the third party in phenomenology, contrasting them with Simmel's position. The latter appears to be characteristic of social science and still affects researchers' focus, for example, in family and fatherhood studies.

Simmel was arguably the first to clearly formulate the difference between groups of two and three elements and based his sociology on this distinction. In Simmel, the dyad and the triad are two separate structures, opposed to each other as relation and interaction. Only the triad is formal and can be studied sociologically. The reason for this lies in that the triad is (1) superpersonal and independent of matter, (2) stable, and (3) represents a pure formal structure, which persists even if the elements are changed. The dyad, on the contrary, cannot produce anything stable, reliable, and socially significant. Its fragility is sufficient to put it aside and ignore it within sociology.

Simmel rejected the dyad because, from his point of view, it depended too much on "matter"-it was overinfluenced by the individual components of a particular situation. The phenomenological method, on the other hand, makes it possible to look at the dyad beyond the "matter" of the specific individual and psychological circumstances of the encounter. Though different in their emphases, Waldenfels, Lévinas, and Marion all reveal something "superpersonal" already in the dyad and uncover the deeper structure hidden behind the concrete circumstances of the encounter between the I and the other. Moreover, in all cases, it turns out that the border between the dyad and the triad is penetrable. There is actually no leap, as Simmel thought; the third party turns out to be co-present in the relationship of the two. Phenomenological interpretation shows the way to a different sociality from the one implied by Simmel's approach, or rather to community. The proposed community could retain the essential from the relationship between two equal but not interchangeable elements and thus would not be based on the primordial war of all against all.

For Simmel, the dyad is a relationship, and the relationship is not social. Building on this, social science naturally arrives at the notion of society as an arena where some equivalent individuals play roles, meet each other, and promote their interests following certain laws. However, phenomenological analysis outlines a certain "middle way" between the closed intimacy of the dyad and the formal neutrality of social structures. Lévinas, Waldenfels, and Marion seek out a path to a "brotherhood" of people as a non-neutral coexistence, in 
which that which is acquired in the encounter between the I and the other is not completely lost. Roughly speaking, Simmel argues that the dyad, unlike the triad, does not produce any social consequences; and the main conclusion of the phenomenological analysis can be formulated as follows: the dyad in which the third party does not arise is poor, and the triad that has lost awareness of the dyad is poor. Sure enough, social order belongs to a different dimension than the encounter with the other in its otherness; however, maintaining the connection between them is extremely important. The trace of the relationship between the two should always be there as comprehension of the injustice of any justice.

Family research, apparently, could benefit most from such an angle. Since the family ceased to be self-evident and self-reproducing reality, the need to look into it is more obvious than ever. In the middle of the $20^{\text {th }}$ century, Simmel's understanding of family as a neutral structure seemed entirely acceptable. Over the last 50 years, family structure and significance, along with the very fact of its existence, have been called into question. The example of fatherhood studies illustrates the key tendency to focus primarily on dyadic structures and to avoid the question of the third party. This corresponds to the emphasis on the privacy of the family and not to its social role. A direct return to the affirmation of family as an unproblematic reality mediating between the personal and the public would sound anachronistic. Still, the search for possible connections between dyadic and triadic structures seems to be of crucial importance if we take into account the results of phenomenological analysis.

\section{References}

Abelin, E. (1971). The role of the father in the separation-individuation process. In J. B. McDevitt \& C.F. Settlage (Eds.), Separation-individuation: Essays in honor of Margaret S. Mahler (pp. 229-252). New York, NY: International Universities Press.

Bernasconi, R. (2005). The third party: Levinas on the intersection of the ethical and the political. In C. E. Katz \& L. Trout (Eds.), Emmanuel Levinas (pp. 45-57). London, UK: Routledge.

Critchley, S. (1999). The ethics of deconstruction: Derrida and Levinas (2 ${ }^{\text {nd }}$ ed.). Edinburgh, UK: Edinburgh University Library.

Dermott, E. (2008). Intimate fatherhood: A sociological analysis. London, UK: Routledge.

Doss, B. D., Rhoades, G. K., Stanley, S. M., \& Markman, H. J. (2009). The effect of the transition to parenthood on relationship quality: An 8-year prospective study. Journal of Personality and Social Psychology, 96(3), 601-619. https://doi.org/10.1037/a0013969

Gatrell, C. (2005). Hard labour: The sociology of parenthood, family life and career. Maidenhead, UK: Open University Press.

Lévinas, E. (1979). Totality and infinity: An essay on exteriority. (A. Lingis, Trans.). The Hague, The Netherlands: M. Nijhoff. (Original work published 1961) 
Lévinas, E. (1981). Otherwise than being: Or, beyond essence. (A. Lingis, Trans.). The Hague, The Netherlands: M. Nijhoff. (Original work published 1974)

Lévinas, E. (1987). The ego and the totality. In Collected philosophical papers (A. Lingis, Trans., pp. 25-45). Dordrecht, the Netherlands: M. Nijhoff. (Original work published 1954)

Marion, J.-L. (2008). The erotic phenomenon (S. E. Lewis, Trans.). Chicago, IL: University of Chicago Press. (Original work published 2003)

Pedersen, F. A., \& Society for Research in Child Development. (1980). The father-infant relationship: Observational studies in the family setting. New York, NY: Praeger.

Peperzak, A. T., \& Lévinas, E. (1993). To the other: An introduction to the philosophy of Emmanuel Levinas. West Lafayette, IN: Purdue University Press.

Simmel, G. (1908). Soziologie: Untersuchungen über die Formen der Vergesellschaftung. Leipzig, Germany: Duncker \& Humblot.

Simmel, G. (1950). The sociology of Georg Simmel. (K. H. Wolff, Ed. \& Trans.). Glencoe, IL: The Free Press.

Tyrell, H., Rammstedt, O., \& Meyer, I. (Eds.). (2011). Georg Simmels grosse «Soziologie»: eine kritische Sichtung nach hundert Jahren. Bielefeld, Germany: Transcript.

Waldenfels, B. (1997). Studien zur Phänomenologie des Fremden (1. Aufl). Frankfurt, Germany: Suhrkamp.

Waldenfels, B. (2006). Grundmotive einer Phänomenologie des Fremden (1. Aufl). Frankfurt, Germany: Suhrkamp.

Waldenfels, B. (2016). Antwortregister (2. Aufl). Frankfurt, Germany: Suhrkamp.

Waldenfels, B., \& Därmann, I. (Eds.). (1998). Der Anspruch des Anderen: Perspektiven phänomenologischer Ethik. Munich, Germany: W. Fink.

Whitaker, C. (1989). Midnight musings of a family therapist. New York, NY: WW Norton. 